Pro-Posições, v. 19, n. 1 (55) - jan./abr. 2008

Quatro vértices e o vento sobre fundo branco

Alan Victor Pimenta*

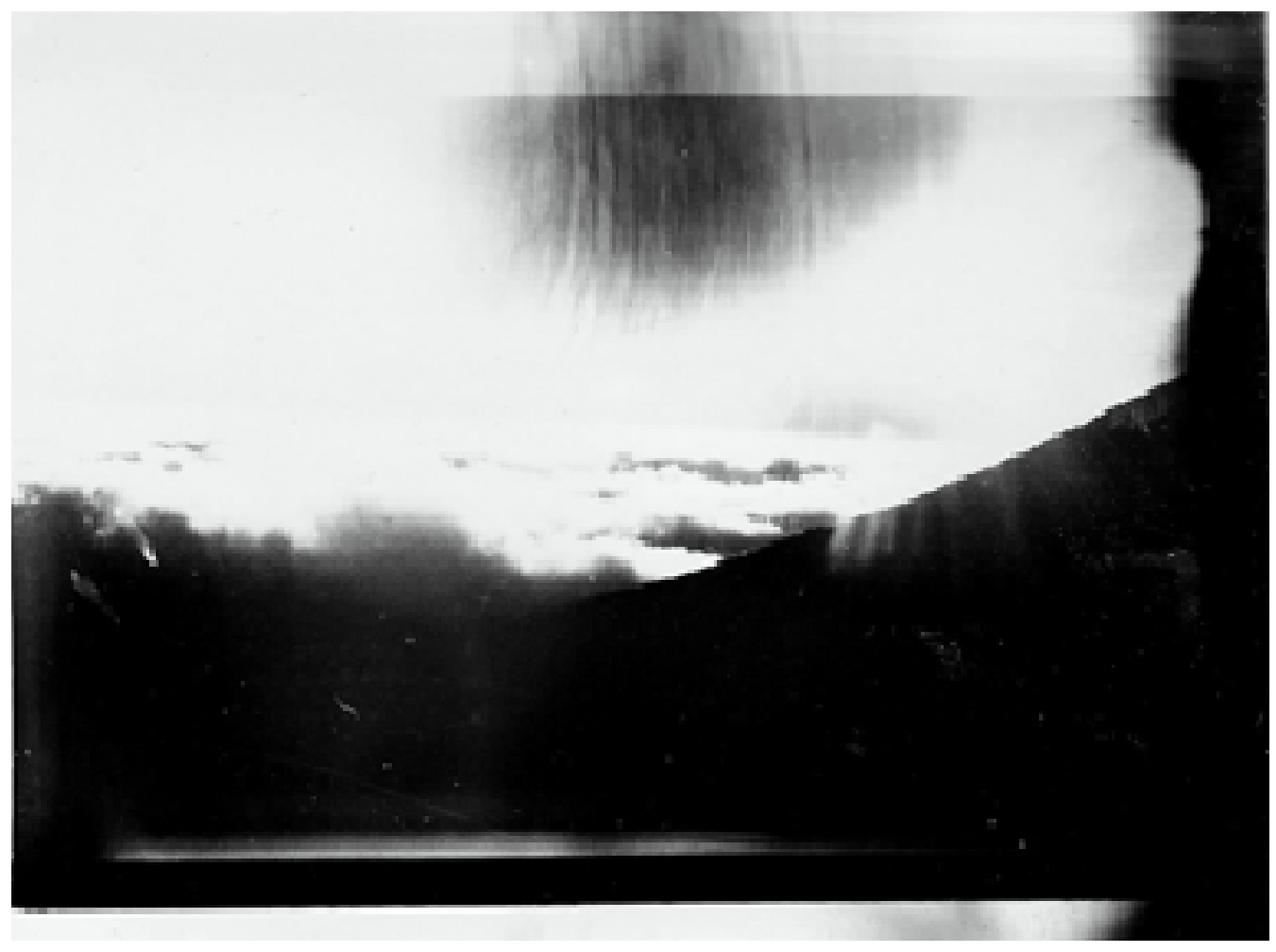


C omporia quatro vértices sobre a luz, grafada. $\mathrm{N}$ em dentro nem fora, à margem, esse espaço repleto do que não se mostra sem que seja al heio. Esse espaço de luz a arder, num sopro que nasce a esvair-se e a castrar meu movimento.

0 interior gravita plenas formas de vazio, plenas formas não estanques, um mal entendido, um que modifique tudo, um sinal negativo na soma. Planejo obter, aqui e ali, uma imagem que se contente com o piscar dos olhos, um arranhão no espelho que me faça recompor tão depressa como se de nada eu fosse feito. C ada espaço grão, cada além orla, cada parte é um vale que abriga os simples. $\mathrm{N}$ as palavras trincadas, nos dentes dos mortos, nos deuses, cada um com sua promessa. $\mathrm{N}$ as multidões, cada um é um centro do universo que se separa na encruzilhada seguinte.

Seria menos espantoso rever meu avô, morrido, que reencontrar aqui seu velho rosto, cuja boca sabe ainda meu N ome, mas cuja substância se refez e na qual o tempo alterou cor e forma. Cuja substância se refez mais de uma vez ao longo desses vinte e cinco anos.

Talvez o que eu queira com essa imagem seja ser um homem sem alma. Talvez meus ardores sejam transbordamento e forma. Talvez eu seja um ensaio. $\mathrm{O} u$ antes, não passe de atitudes que às vezes são interrompidas por uma paisagem à qual me consinta viver.

\section{O respiro}

Como tempo, os ventos se tornaram transpassantes de mistérios. Aquele vento esbarrado em cantos, cada um, um sortilégio e um gosto de textura. D e todos os lugares chegavam ventos, aquela flauta redançava meu quarto no espaço da cortina com o canto da parede. Q uando chovia era porque 0 ar carregava molhadas palavras que escorriam verticais figuras, eu ficava olhando cada uma daquelas palavras ajuntar mais outras que viravam todas uma poça de conversas; aquelas falas todas falam da gente quando a gente ol ha brincando de improvisar espelho. $\mathrm{N}$ um desses dias entendi que 0 vento me guardava o rosto quando soprava, esse rosto que eu só via quando virava espelho de água do vento; e que o vento andançava por aí me carregando em segredo com mais um punhado outro de lembranças minhas, umas macias, outras agitadas e que eu não queria. Eram assim os ventos, sopravam meu dentro e os cantos, a casa que é aquela e essa mesma onde moro, a letra A no meu nome, a cera da luz que escorre. Era

\footnotetext{
Fotógrafo e historiador. Mestre em Educação e doutorando no Laboratório de Estudos Audiovisuais OLHO, Faculdade de Educação, Unicamp. Autor de diversos trabalhos de fotografia, criação, edição e cinegrafia, entre eles, A criação do brasil e Estrangeiro sobre a terra, no Laboratório de Estudos Audiovisuais OLHO, FE, Unicamp. russo333@ hotmail.com
} 
assim que o vô ensinava a ver o tempo. À tardinha se agachava e a gente trepado no tronco da árvore caída, o vô na palha, eu mudo, a gente olhava; olhar era ali uma oração calada, porque a gente que é assim sabe bem o que falar direito. 0 nome do pasto era das O liveiras, não tinha uma e só fui saber o que era quando mais moço. Eu ficava ali, eu só e o vô comigo, e na gente uma cara amarela daquela luz que morre. Q uando tinha tempestade eu me gostava, o vento estrondeava e fazia uma faísca branca que deixava o céu todo roxo, era um tempo que era um nada, São Jerônimo, a vó gritava, e eu gostava desse santo porque era santo de riscar o céu com chispa e que escrevia sem parar naquele livro que guarda todas as palavras que a vó deixava sempre aberto, na mesma página, ela tinha bem no alto o nome de um homem que se chamava Jó, e uma porção de números que não lembro quais. $\mathrm{N}$ enhum dos dois era de fala. $\mathrm{N}$ ão me pergunto. As palavras que saíam eram resvoadas de dentro antes de encontrar a boca. Falavam com o barulho do vento que vem e machuca 0 ar quando a boca se mexe, dizendo. As palavras saíam daquele tempo parado no interior e se exilavam em meus ouvidos. $\mathrm{N}$ a verdade eu só via a boca se mexendo, sem ouvir. Agora pouco importa, pouco importam agora os nomes que eu ouvia. Agora só importa ver a boca se mexer, adivinhando o que dizia. São enormes meus lugares, o vento, dentro de mim é que ele cabe. $\mathrm{N}$ ão há mais que silêncio, silêncio morrido no faltar da fala. ( $\mathrm{N}$ ão me pergunte das rosas, não vê que vem delas todo o perfume e sua boca é a única flor? Para o verde, verde, para o olho, luz. E quando me encontrar em mim vou acabar para o tempo e vou estar, daqui dos olhos adentro, verdeolhando o campo, a linha rosa que é a pele salpicar o céu, com os poentes do sol em janeiro, feverestivando um canto, aonde a lua vai onde mais se esconde, onde as vistas perdem. $\mathrm{N}$ ão me pergunte das sombras, não vê que o corte te performa o corpo e tudo o que é, é o todo?)

\section{As vistas}

$\mathrm{N}$ ão encontrei palavras de luz e sombras, de correntes e silêncios. Pleno de paixões, repleto de histórias, na noite densa, fui repleto de palavras, palavras eternas como o tempo, a matéria, palavras que pesam como mãos, cintilantes como estrelas. D e minha cabeça, de minha carne, de meu coração, estive junto das palavras, as palavras necessitam de mim. M inhas palavras necessitam de mim e nelas fui triste, amável, fui alegre, cheio de esperança, fui corajoso, heróico, através de mim as palavras foram homens. As palavras do vô me leram no silêncio, viram no invisível, me inventaram uma forma de ser pra dar fim ao mundo. Invento um nome. Digo coisas. O lho por longos tempos. Perco um nome que combine com meu jeito e meu nariz. O Iho solto e a cada dia vejo um outro. 0 vô é que era artista, me basto. $\mathrm{N}$ outro dia de andança com ele veio 
um homem, era rico, de perto virou pobre, quando passou voltou a ser rico: bem quieto, fio, a conta do tempo dá o tamanho da coisa. Foi isso e um passo depois do outro. $\mathrm{N}$ ão pergunto. $\mathrm{O}$ vô é homem que vê e quem vê sabe ver no invisível da visão que o vô mostra. M ostrava a rocha que a luz mostrava, pra eu ver que tudo era luz e a luz barrava um jeito de rocha. Era noite e o vô falava uma fala trancada de noite. M e basto. 0 vô dizia e eu não sabia mais o que era o vô e o que era noite, era clarão de dia. 0 que eu via era uma vista redonda que às vezes queria ser um quadro, mas uns lados eram negros, porque a luz quando é muita vira negra. Às vezes eu via desenhos que chamavam nuvens. Às vezes eram gentes que falavam sem parar, noutras eram só desenhos nas nuvens. N ão achei o possível de pensar que eram nuvens porque 0 vô sempre voltava a falar e eu ouvia as palavras das nuvens: óia fio; e mais um não sei que sempre parava no dizer do: ó, fio. Não sei de que jeito as coisas se faziam, mas era tudo um olhar e eu olhava aquele fio de coisas muitas se cruzando e me fazendo ver as falas do vô no lugar que eu olhava de feitiço.

\section{A fala}

Venha a mim, me leve, me saiba saudade a me lavar, que impertinente a mim se me botou, seus ol hos de mostrar versos sutis, pálido céu. Te enxergo com esses meus olhos que ao pó tornam mais de uma vez ao dia. N outro dia me fantasiei de lágrimas, com despejo de cores e calores, segui seus caminhos numa via de leite e parei, a asa se vai, um choro aberto sobre a terra. Situação, era domingo pra quem inventou o domingo, em mim sempre foi um dia só, segurei vertigens, inventei as letras do alfabeto e coloquei números entre elas para que ninguém descobrisse sua falta de mistério, manuscrevi princípios, toquei os bichos que cantavam de volta pro mato, fiz perjúrios e sentei sobre eles, mas, quando esquentaram, quebraram a casca e correram todos sem se dar por satisfeitos, inqueri, chamei por minha falta de coragem, ela veio e foi embora, tirei as botas. Foi antes, foi bem antes de eu ter nascido que a vida foi só sangue, e o sangue já se decidia sobre que cor teria e quais seriam minhas vestes. Minha boca me veste, tudo recua, pequenos becos entre as rochas escondem lagartos, o deus novo e marcial espreita, vacilo ácido, minha vida celeste, as nuvens vistas de longe são outra coisa e a mesma coisa, se insinuam à boca e eu cismo, e seu mundo e seu sabor se tornam desertos dentro de mim e dormem no fundo baboso dos meus rios. Abro a boca, minha boca procura nos ares o reflexo baixo das nuvens, por debaixo de todos os assombros, todos os martírios, e lá na frente são outros ares soluçantes nesse rolo de águas. Se acaso protesto, dou não mais que aquilo que fica pra cá do grito, dou o impossível e dou o segredo, o a mais da insinuação. 


\section{O sangue}

Talvez o que eu veja quando tranco os olhos não seja luz, me ouço. Resta um agora me sentindo a menos, matéria confusa e densa, minha essa matéria crua de carne mirrada e seca, viva pelo coalho amarelado quando seca, amarelo porque é seco, minha matéria essa erguida adentro por ossos quase ossos, esses ossos que são ossos da vó. 0 que me fiz do vô fiz em entranhas. Por essa su'alma inacabada, essa minh'alma que é meu $U \mathrm{~m}$, meu poço cavado à mão sem desespero infantil, meu sopro, meu vôo passado rasante, passado presente o futuro, meu eu de voz rosnante, sussurro, fresta, o rasgo, minha hora à hora vazia. Talvez 0 ar. 0 ar rebelde das lembranças, que me alimenta de um escuro grosso e seco, um vinho sem pouso. 0 respiro encardido da memória de Lúcifer inflamada na carne até 0 silêncio. E talvez seja isso mesmo, o encontro que não sei, 0 encontro do ar da alma das lembranças nas vermelhas águas que o corpo pulsa. $M$ ais de uma vez me vi no fim, sem reservas. M eus pedaços esquecidos me salvaram do fogo e do amor. Já amei sozinho comigo. Já encontrei também o amor do amor, em carne plena e susto vário. Amei no exílio e na preguiça. Escolhi. D escobri minha inconstância e aventura, meu outro sinal, fui muitos e amei. Só, não sei, dançarejo ignorâncias inventivas, e minhas sabedices vêm de fontes que não sei. Q uem fala por mim? Q uem beija por minha boca? M e sinto estacado no arco das rochas, meu berço mestiço, e meu ventre empurra a corda e afina com os ventos dos ares. Enrouqueço. Ú mido de ventos, na espuma da água dos meus ventos, me espatifo nas dedilhações brutas da sutileza do frio. Por que o dono de minha vida não me ouve? Sei que não sei por mim. Sabem por mim os rios de luz sobre a rocha. $D$ ançarejo ignorâncias inventivas. $M$ inha dança é tão solta como dor que afina. M inha dor é tão vária que possui mil vasos de correr meu corpo. Eu transmudaria meu desejo mais meu numa dança mais sutil que essas ondas grossas e oleosas. Porque meus jeitos nascem do incêndio dessa luz na rocha, que tem vasos mais dilatados que os meus. Sua primeira voz foi um Verbo. Essas rochas são um Verbo cujas preces me fizeram com dinheiro vendido. Como posso me fazer assim? Ante o ouro pelo qual me sacrificam os homens, trocando a luz que incendeia encravada rocha pelo outro tesouro que dorme incrustado na pedra, sendo ele um ou outro momento da obra. É noite e tudo é noite. M eus olhos são noite. $\mathrm{N}$ ão enxergo as braçanhas da noite, só a enorme cidade que me espalha e me disfarça. M e divido. M eu sopro se agarra, não sai. Abro os olhos e meu olhar procura nos ares o peito da rocha, a água das nuvens. São formas. Elas fogem. Se abrem e se fecham. $\mathrm{Na}$ noite, tudo é noite. M e guardo. Sou multidão acordada na rocha, morte nascida de dia, mais claro que os vulcões vivos e adjetivos. R ecuso a paciência e a espera. Sou a rocha olhada. Eu sigo o veio e o metal na densidade de luz que aninha a 
terra em profundezas. M eus olhos me intrigam, das nuvens, pesados e ilusórios. $\mathrm{N}$ ão continuo. Então a rocha se abriria clara e orgulhosa. Eu não seria tãosomente o peso. Escuto os ventos, a multidão, vertical e sutil. Cada sopro apenas se movimenta e se mistura no ar. Estive aqui e ali, e se a terra gira não me preocupa saber em que ponto dela estou, menos ainda quando me deitar. Saltei de início sobre a laje do meu corpo, meus olhos foram de espanto e parados, fechei minha pálpebra de couro para me proteger da luz. Criança, minha primeira lágrima se fez do tempo, passei a falar o que não sabia de aprendido dos outros, como quem circunda um círculo sem penetrá-lo, e na claridade me vi espiar por entre as folhas, leve como um pássaro que a cada espaço ocupa um instante novo, quando senti pela primeira vez foi um cheiro de metal vermelho escorrido das entranhas, me arranquei do estanque para 0 eterno movimento. $M$ al saído dos ventos do meu sono, eu disse, cego de luz: tenho vinte e cinco anos e sobre a rocha sou. D e pés desnus profetizo e tombo os olhos. E eu que pensei que essa pedra aconteceria de repente querer 0 sol se encher com meu sangue antigo, lançando seus dardos de cobre com um vento zunindo em meus ouvidos e já não valeria nada tudo o que eu sabia, me espinhaço agora o couro em pontas de luz metálica trabalhando o rasgo à hora larga do silêncio do meu ninho, enquanto cada palavra persegue fremente um veio vinho, sou menino. Súbita insônia rondando quieta meu sono de rocha, pisoteando as páginas de muitos livros, colhendo gravetos e um inquérito, quantas mulheres, eu sabia, simplesmente forjava o punho, decretava a hora, mas eu entrei na cidade e meus pés não andaram, inimigos grandiosos e história completa, a revoada armada me riu seu riso de garoa, a primeira hora foi obedecer, opus; a segunda foi mandar, obedeci; a terceira foi sondar, mas me equilibrei num pé e não dormi; todas as outras foram roubar e matar, beijei de mãos abertas; a maior de todas foi esquecer, provei do pó da rua e me lembrei, a cidade em luz e música passou sua mão na bruma dos meus olhos, eu com a flor roubada na abertura da camisa gritei um eco fora de cena, pois então a cidade se fez mãe e descarnei nela noite e dia, na rocha grave e seu frio ácido para o vinho do corpo; dancei sem tontura, quis ser miragem, feioso e leal, eriçado em boca de homem, o sal da verdade se tornou salobro à presença do passado. De, pois que descansei, a rocha me levou ao chão da terra, onde 0 calor é ouro do dia incrustado em noites de pedra, onde tudo é seio morro, entre 0 sangue que corre nos morros a convulsão tem às vezes seus direitos, os gigantes da mina com seus anões ensinados traem a cidade e seus chãos iluminados. Agora é o que foi. Enquanto não nascer, a tempestade me acordará do seio do horizonte, toda ela impaciente, tem mil punhos, no desejo. N esse momento visto de rocha. Ao sol e às chuvas e aos ventos que fazem vingar ou findarem as lavouras, apesar do enxerto de várias geografias, sobre todas as 
igrejas e sermões, mais antiga que qual quer discernimento, a rocha e seus líquidos maduros serão matéria do dizer: está escrito. Sob os vales que fazem um corpo, pondo folhas em perturbação, feiticeiros viajam em planos escuros numa caravana vermelha, povoam nosso cheiro de resinas e ungüentos, esfregam nossos narizes com o pó de nossa carne, cavam nossos sebos esfomeados, não adianta deixá-los de lado, nada de querer dar fim a essa fala remendada. $N$ os recolhermos na casa velha da infância, sentimos suas mãos em baixo de nossos passos, devolvemos às raízes a origem de nossos pés, exploramos o silêncio dos corredores, as rachas nas paredes e, inflamando as narinas, revivemos os suspiros coalhados e os sussurros de vida, deixamos as preces, incendiamos a fé e as sombras enquanto sobem gemidos subterrâneos pelos rangidos da pedra, essa argamassa batida, fazemos da carne a maior casa, suando o sangue nessa fenda esquálida, rachando as palmas, apontando nossa presença no íntimo da casa velha, espiando pelas frinchas feito bicho, o mesmo aço intermitente do grito, somos eu nascido.

Foto: Parque Itatiaia, de Alan Victor Pimenta.

Recebido em 20 deagosto de 2007 eaprovado em 23 denovembro de2007. 